\title{
Outcome of Elderly Population Undergoing Primary PCl in a Tertiary Hospital in Bangladesh
}

\author{
Sahela Nasrin, ${ }^{1}$ Shitil Ibna Islam, ${ }^{2}$ F. Aaysha Cader, ${ }^{3}$ Masuma Jannat Shafi, ${ }^{4}$ M. Maksumul Haq ${ }^{5}$
}

Objective: To evaluate in-hospital and 1-year outcomes of primary percutaneous coronary intervention (PPCI) in elderly patients with ST-elevation myocardial infarction (STEMI).

Methods: All patients aged $\geq 65$ years presenting with STEMI and undergoing PPCI at Ibrahim Cardiac Hospital \& Research Institute, Bangladesh from January 2015 to August 2017 were consecutively included in the study based on predefined eligibility criteria. Data pertaining to angiographic characteristics, procedural variables, in-hospital and 1 -year outcome variables were recorded and analyzed with the help of descriptive statistics and Chi-square Test.

Results: The mean age of the patients was $69.2 \pm 5.2$ (range: $65-85$ ) years with male to female ratio being $4: 1$. The patients were predominantly diabetic (78\%) followed by hypertensive $(74 \%)$ and dyslipidaemic $(70 \%)$ smoker $(54 \%)$. Half of the patients presented with anterior myocardial infarction (MI), 30\% had inferior MI, 12\% with right ventricular (RV) extension and $8 \%$ with inferolateral extension. About one-quarter (24\%) had arrhythmia with complete heart block (CHB). The culprit arteries were LAD (50\%), followed by RCA (42\%) and LCx ( $8 \%)$. Nearly half (46\%) had single vessel disease, $34 \%$ double and $20 \%$ triple vessel disease. Majority (80\%) received a single stent and $20 \%$ required two stents with mean diameter and length of the stents were $2.9 \pm 0.4 \mathrm{~mm}$ and $27.3 \pm 7.9 \mathrm{~mm}$ respectively. Intracoronary eptifibatide was used in $20 \%$ cases. In terms of left ventricular ejection fraction (LVEF), $58 \%$ and $28 \%$ had mild and moderate LV systolic dysfunction respectively. The mean duration of hospital stay was $4.0 \pm 1.9$ days. About $18 \%$ required repeat hospitalization. Overall, $7(14 \%)$ patients died (4 during their stay in the hospital due to cardiac cause and 3 during follow up due to non-cardiac causes). At 1 year follow up, in-stent restenosis was seen in 1 case followed by target vessel revascularization (TVR). The Association between age and outcome revealed that advanced age (age $\geq 75$ years) was an important predictor of in-hospital and one-year outcome with Relative Risk (RR) of having unfavorable outcome was $>5$-fold (95\% CI: $1.6-19.5)$ in patients of advanced age than that in patients of age $<75$ years $(p=0.008)$.

Conclusion: Primary PCI is a feasible treatment option for elderly Bangladeshi patients presenting with STEMI with fewer in-hospital and 1-year follow up deaths. Adverse cardiovascular events are even less. Advanced age (age $\geq 75$ years) is an important determinant of adverse cardiovascular events including mortality, probably because of more medical co-morbidities associated with advanced age.
\end{abstract}

Key words: Elderly population, primary PCI, outcome etc.

\section{INTRODUCTION:}

Cardiovascular disease is the most common cause of morbidity \& morality in persons aged 65 years and older, and its incidence increases with age. ${ }^{1}$ The terms "elderly" and "older adults" usually refer to persons older than 65 years..$^{2,3}$

\section{Authors' information:}

'Dr. Sahela Nasrin, MBBS, MCPS (Med), MD (Card), Associate Professor \& Consultant, Ibrahim Cardiac Hospital \& Research Institute, Dhaka, Bangladesh.

${ }^{2}$ Shitil Ibna Islam, MS in Environmental Science (KU), MS in Health Economic (DU), Research Officer, Ibrahim Cardiac Hospital \& Research Institute, Shahbag, Dhaka, Bangladesh.

${ }^{3}$ Dr. F. Aaysha Cader, MBBS, MD (Cardiology), MRCP (UK), Assistant Professor, Department of Cardiology, Ibrahim Cardiac Hospital \& Research Institute, Dhaka, Bangladesh.

${ }^{4}$ Prof. M. Maksumul Haq, MBBS, FCPS, FRCP, FACP, Professor \& Head, Department of Cardiology, Ibrahim Cardiac Hospital \& Research Institute, Dhaka, Bangladesh.

Correspondence: Dr. Sahela Nasrin, Phone: +8801766089094 E-mail:nasrin_jhumur@hotmail.com 
Older adults are rapidly increasing in the United States and by the year 2030, 1 of every 5 individuals might be older than 65 years. ${ }^{4}$ In Bangladesh due to improved quality of life the number of people over 60 years is increasing rapidly. ${ }^{5}$ In 2025 , one in every 10 people will be 60 or above, and in 2050, one in every five people will be "elderly". ${ }^{6}$ In Bangladesh population aged 65 or above was reported to be $5.1 \%$ (as a percentage of total) in 2018 (according to the World Bank Development indicators). As average life expectancy of Bangladeshi people is increased (73.5 years), ${ }^{5}$ a higher proportion of elderly patients are expected to present with STEMI. As these patients may present with atypical symptoms, the diagnosis of MI may be delayed or missed. ${ }^{7}$ In addition, the elderly would have more comorbidities and are less likely to receive reperfusion therapy compared with younger patients. ${ }^{8,9}$ Among many factors, age is one of the predominant reasons of deferred PCI in elderly patients, from the patients' themselves or from patients' family perspectives.

Elderly patients are at particular risks of bleeding and other complications from acute therapies. The renal function tends to decrease, \& the prevalence of comorbidities becomes high with advanced age. ${ }^{10}$ Particular attention, therefore, must be paid to the proper dosing of antithrombotic therapies considering renal function, frailty, or comorbidities, and radial access should be preferred whenever possible. ${ }^{10}$ There is no upper age limit with respect to reperfusion, especially with primary PCI. ${ }^{11}$ Elderly patients are at high risk when they present with STEMI, a condition that often accounts for morbidity and death. Reasons for the high risk include atypical presentation, delays in seeking medical care, management by non-cardiologists, and, frequently, admission to hospitals that have no catheterization facility, which is particularly relevant to Bangladesh owing to limited numbers of catheterization laboratory facilities. ${ }^{12,13}$ Mortality and morbidity have been shown to significantly reduce in elderly population when primary PCI was done in appropriate time frame, in comparison with thrombolytic therapy or medical management alone. ${ }^{14}$

To the best of our knowledge, there is insufficient data about the safety, efficacy and outcome of primary PCI in an elderly cohort of patients aged $\geq 65$ years in a Bangladeshi population. Therefore, this study was done in older ( $\geq 65$ years) Bangladeshi patients undergoing PPCI for STEMI to evaluate their in-hospital and 1-year outcome.

\section{METHODS:}

STEMI patients aged $\geq 65$ years who underwent primary PCI at Ibrahim Cardiac Hospital \& Research Institute, Bangladesh from January 2015 to August 2017 were the study population. A total of 50 such patients were consecutively included in the study. The clinical, angiographic, procedural, in-hospital and 1-year follow-up outcomes were collected in a specifically designed study database. Patients were followed up to 1 year via personal or familial telephone contact. The following major adverse cardiac events were defined: a) mortality (in-hospital and at follow up), b) cardiovascular death, as death due to cardiovascular causes, including unexplained sudden death, c) myocardial infarction if the event fulfilled criteria meeting the fourth universal definition of myocardial infarction, d) repeat revascularization, including any revascularization procedure in previously treated culprit lesions, e) stent thrombosis, classified according to the Academic Research Consortium (ARC) criteria and f) bleeding, scored according to the classification of the Bleeding Academic Research Consortium (BARC) (Bleeding was considered major if it had a BARC score > 2), g) stroke. Any of the above adverse events including mortality that developed among the patients during hospital stay and 1-year follow up period was considered as unfavourable outcome. Statistical analysis was done with the help of SPSS (Statistical Package for 
Social Sciences), version 25.0. The test statistics used to analyze the data descriptive statistics and Chi-square $\left(\chi^{2}\right)$ Test. Association between age of the patients and outcome was analyzed using Chi-square $\left(\chi^{2}\right)$ Test with level of significance being set at $5 \%$.

\section{RESULT:}

Baseline and clinical characteristics of the patients are presented in Table I. There were $41(82 \%)$ males and $9(18 \%)$ females. The mean age of the patients was $69.2 \pm 5.2$ (range: $65-85$ ) years. The predominant comorbidities were diabetes (78\%) followed by hypertensive (74\%) dyslipidaemic $(70 \%)$ and smoker $(54 \%)$. The mean duration of symptoms was $5.2 \pm 2.9$ (range: $0.5-12$ ) hours. Forty four percent of the patients presented with acute kidney injury (AKI) and $2 \%$ with cardiac arrest. Serum Glutamic-Pyruvic Transaminase (SGPT) level was $47.4 \pm 7.3$ (range: $12-380$ ) U/L. $\mathrm{N}$-terminal pro b-type natriuretic peptide (NT-pro-BNP) was raised in 38\%, normal in $16 \%$ and was not done in $46 \%$ patients.

Nearly half ( $46 \%$ ) of the patients had single vessel disease (SVD), 34\% double vessel disease (DVD) and $20 \%$ triple vessel disease (TVD). The infarct-related arteries (IRAs) were LAD (50\%), RCA (42\%) and LCX (8\%). Majority (98\%) of the procedures was done through radial access. Slow flow was found in $10 \%$ cases. Intracoronary eptifibatide was used in $20 \%$ patients and thrombus extraction was done in $2 \%$ patients (Table II). Nearly $60 \%$ of the patients had mild and $28 \%$ moderate LV systolic dysfunction (Fig.1).

In terms of diagnosis, $30 \%$ had Inferior MI and $22 \%$ had anterior MI, $14 \%$ had extensive anterior and another $14 \%$ anteroseptal MI. Inferior MI with Right Ventricular (RV) infarction and inferolateral extension were $12 \%$ and $8 \%$ respectively (Fig. 2 ).

Majority $(80 \%)$ of the patients required single stent to be implanted and $20 \%$ required two stents. In all cases, a drug-eluting stent (DES) was implanted. Both DES and bare metal stent
(BMS) were implanted in $8 \%$ cases where more than one stent was required. Mean stent diameter was $2.9 \pm 0.4) \mathrm{mm}$ (range was $2.25-4.0 \mathrm{~mm}$ ). The mean stent length was $27.3 \pm 7.9$ (range: 12-38) $\mathrm{mm}$.

\begin{tabular}{|c|c|c|c|}
\hline $\begin{array}{l}\text { Baseline \& clinical } \\
\text { characteristics }\end{array}$ & Frequency & Percentage & $\begin{array}{c}\text { Mean } \pm \text { SD } \\
\text { (range) }\end{array}$ \\
\hline Age (years) & --- & --- & $\begin{array}{c}69.2 \pm 5.2 \\
(65-85 \text { years })\end{array}$ \\
\hline \multicolumn{4}{|l|}{ Sex } \\
\hline Male & 41 & 82.0 & --- \\
\hline Female & 9 & 18.0 & --- \\
\hline Smoking & 27 & 54.0 & --- \\
\hline Diabetes & 39 & 78.0 & --- \\
\hline HTN (Hypertension) & 37 & 74.0 & --- \\
\hline \multicolumn{4}{|l|}{ SOB (shortness } \\
\hline of breath) & 11 & 22.0 & --- \\
\hline Chest pain & 49 & 98.0 & --- \\
\hline Syncope & 1 & 2.0 & --- \\
\hline Cardiac arrest & 1 & 2.0 & --- \\
\hline $\begin{array}{l}\text { History of coronary } \\
\text { artery disease }\end{array}$ & 7 & 14.0 & --- \\
\hline CKD & 10 & 20.0 & --- \\
\hline Stroke & 6 & 12.0 & --- \\
\hline $\begin{array}{l}\text { Duration of } \\
\text { symptoms (hours) }\end{array}$ & --- & --- & $5.2 \pm 2.9(0.5-12)$ \\
\hline Hypothyroidism & 1 & 2.0 & --- \\
\hline \multicolumn{4}{|c|}{$\begin{array}{l}\text { Chronic obstructive } \\
\text { pulmonary disease } \\
\text { (COPD)/Bronchial asthma } 7\end{array}$} \\
\hline Prior MI & 1 & 2.0 & --- \\
\hline Prior PCI & 1 & 2.0 & --- \\
\hline Oedema & 1 & 2.0 & --- \\
\hline AKI & 22 & 44.0 & --- \\
\hline SGPT (U/L) & --- & --- & $\begin{array}{c}47.4 \pm 7.3(12-380) \\
\text { Mean } \pm \text { SEM }\end{array}$ \\
\hline \multicolumn{4}{|l|}{ NT-pro BNP } \\
\hline normal & 8 & 16.0 & --- \\
\hline raised & 19 & 38.0 & --- \\
\hline not done & 23 & 46.0 & --- \\
\hline
\end{tabular}


Table IV demonstrates in-hospital outcomes of patients. Total in-hospital mortality was $4(8 \%)$. One of them expired during the procedure with anterior MI, 1 following PCI on $2^{\text {nd }}$ day due to cardiogenic shock, 1 due to reinfarction and the last one due to sepsis followed by cardiogenic \& septicemic shock. Eight percent developed cardiogenic shock, $8 \%$ required mechanical ventilator, 24\% had arrhythmia (CHB 12\%, VT $6 \%, A F 4 \%$ and AV block 2:1 2\%). Mean duration of hospital stay was $4.0 \pm 1.9$ days (range: $2-11$ days).

\begin{tabular}{|c|c|c|}
\hline Angiographic \& procedural variables & Frequency & Percentage \\
\hline \multicolumn{3}{|l|}{ No of vessel involved } \\
\hline Single vessel disease (SVD) & 23 & 46.0 \\
\hline Double vessel disease (DVD) & 17 & 34.0 \\
\hline Triple vessel disease (TVD) & 10 & 20.0 \\
\hline \multicolumn{3}{|l|}{ IRA } \\
\hline LAD & 25 & 50.0 \\
\hline LCx & 4 & 8.0 \\
\hline RCA & 21 & 42.0 \\
\hline \multicolumn{3}{|l|}{ Access } \\
\hline Radial & 49 & 98 \\
\hline Femoral & 1 & 2 \\
\hline Intracoronary eptifibatide & 10 & 20.0 \\
\hline Slow Flow & 5 & 10.0 \\
\hline Pre dilatation & 43 & 86.0 \\
\hline Post dilatation & 10 & 20.0 \\
\hline Temporary pacemaker (TPM) & 6 & 12.0 \\
\hline Thrombus extraction & 1 & 2.0 \\
\hline
\end{tabular}

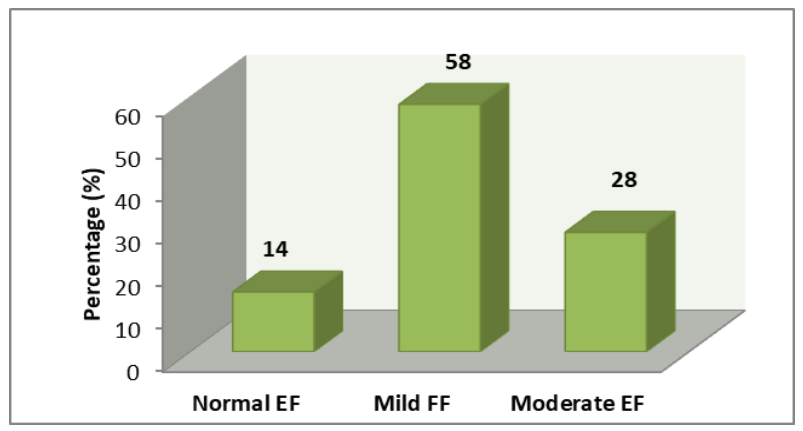

Fig I: Distribution of patients by their ejection fraction $\%$

In nearly $70 \%$ of the cases, further revascularization was not needed due to diffuse nature of the disease or the lesion was of moderate type. Only
$17.4 \%$ underwent further revascularization of non-culprit lesions either before discharge in the same admission or later with subsequent admission $\& 13 \%$ refused to receive stent of the non-culprit lesion (Fig. 3).

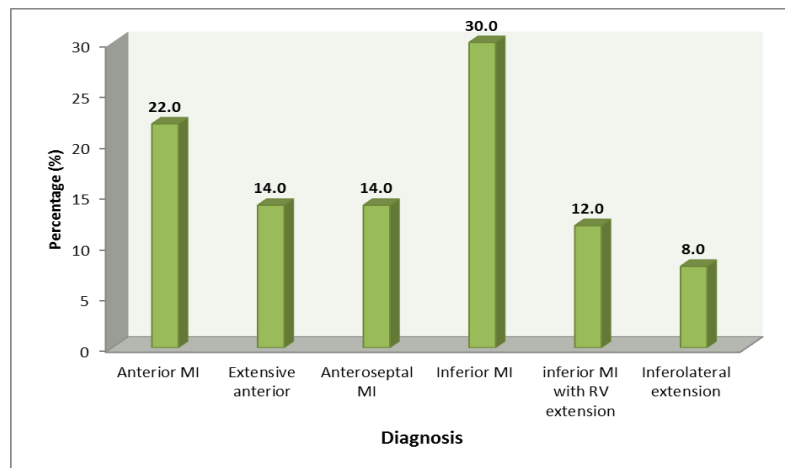

Fig 2: Distribution of patients by their diagnosis

Follow up after 1 year was done over telephone communication with patients themselves or their relations. Follow-up data was available for 45 patients. Follow up of one patient was not possible due to loss of contact. Of the 45 patients followed, there was a further $3(6.67 \%)$ patients died; all of them with non-cardiac causes. Further hospitalization was needed in $17.78 \%$ cases. In-stent restenosis (ISR) was observed in $1(2.22 \%)$ patient followed by TVR. Ischemic stroke developed in $2(4.44 \%)$ patients (Table V).

\begin{tabular}{|c|c|c|c|}
\hline Stent & Frequency & Percentage & Mean \pm SD (range) \\
\hline \multicolumn{4}{|l|}{ Stent number } \\
\hline Single & 40 & 80.0 & --- \\
\hline Double & 10 & 20.0 & --- \\
\hline \multicolumn{4}{|l|}{ Stent type } \\
\hline DES only & 46 & 92.0 & --- \\
\hline BMS only & 0 & 0.0 & --- \\
\hline DES \& BMS both & 4 & 8.0 & --- \\
\hline Diameter of stent $\mathrm{mm}$ & $\mathrm{nm}$--- & --- & $2.9 \pm 0.4(2.25-4)$ \\
\hline Length Stent mm & --- & --- & $27.3 \pm 7.9(12-38)$ \\
\hline
\end{tabular}

The hypothesis that advanced age is likely to cause unfavorable outcome in patients undergoing primary PCI was tested with crosstab (Chi-square) analysis. The analysis revealed that advanced age (age $\geq 75$ years) was an important predictor of 
in-hospital and one-year outcome with Relative Risk (RR) of having unfavorable outcome was > 5 -fold (95\% CI: 1.6-19.5) greater in patients of advanced age than that in patients of age $<75$ years $(p=0.008)$ (Table VII).

\begin{tabular}{|c|c|c|c|}
\hline $\begin{array}{l}\text { In hospital } \\
\text { outcome }\end{array}$ & Frequency & Percentage & $\begin{array}{c}\text { Mean } \pm \text { SD } \\
\text { (range) }\end{array}$ \\
\hline In hospital mortality & 4 & 8.0 & --- \\
\hline \multicolumn{4}{|l|}{ Time of death } \\
\hline During procedure & 1 & 2.0 & --- \\
\hline After procedure & 3 & 6.0 & --- \\
\hline \multicolumn{4}{|l|}{ Arrhythmia } \\
\hline $\mathrm{CHB}$ & 6 & 12.0 & --- \\
\hline AV block 2:1 & 1 & 2.0 & --- \\
\hline VT & 3 & 6.0 & --- \\
\hline AF & 2 & 4.0 & --- \\
\hline Hypotension & 4 & 8.0 & --- \\
\hline \multicolumn{4}{|l|}{ Acute Left Ventricular } \\
\hline Failure (ALVF) & 17 & 34.0 & --- \\
\hline Cardiogenic shock & 4 & 8.0 & --- \\
\hline Bleeding/ hematoma & 0 & 0.0 & --- \\
\hline Ventilator required & 4 & 8.0 & --- \\
\hline \multicolumn{4}{|l|}{ Length of hospital stay } \\
\hline in days $(n=46)$ & --- & --- & $4.0 \pm 1.9(2-11)$ \\
\hline
\end{tabular}

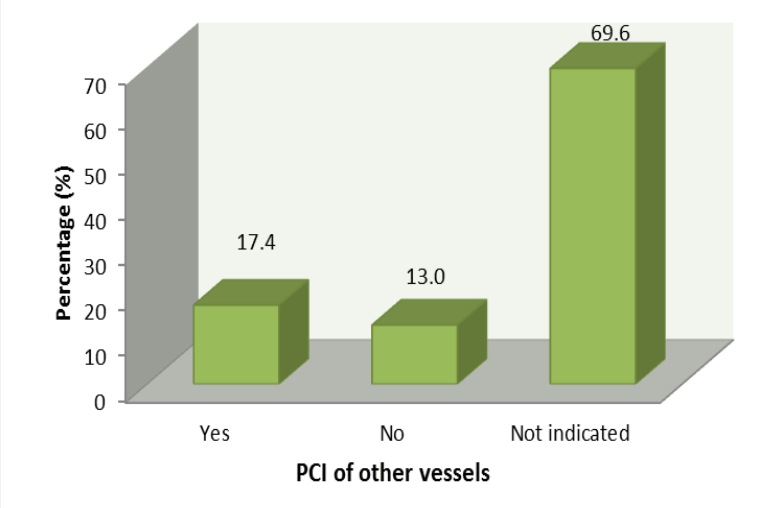

Fig 3: distribution of patients undergoing revascularization of non-culprit lesions

\begin{tabular}{|c|c|c|}
\hline \multicolumn{3}{|c|}{$\begin{array}{l}\text { Table V. Distribution of patients by follow-up findings at } \\
1 \text { year }(n=45)\end{array}$} \\
\hline Findings & Frequency & Percentage \\
\hline Death at follow-up & 3 & 6.67 \\
\hline Causes of death: Non cardiac & 3 & 6.67 \\
\hline Subsequent hospitalization & 8 & 17.78 \\
\hline Chest pain & 2 & 4.44 \\
\hline SOB & 4 & 8.89 \\
\hline Stroke & 2 & 4.44 \\
\hline ISR & 1 & 2.22 \\
\hline TVR & 1 & 2.22 \\
\hline \multicolumn{3}{|l|}{ Creatinine } \\
\hline normal & 28 & 60.9 \\
\hline Raised creatinine & 7 & 15.2 \\
\hline not done & 10 & 23.9 \\
\hline \multicolumn{3}{|l|}{ LV systolic dysfunction } \\
\hline No LV systolic dysfunction & 9 & 19.6 \\
\hline Mild LV systolic dysfunction & 16 & 34.8 \\
\hline Moderate LV systolic dysfunction & 3 & 6.5 \\
\hline Echo not done & 17 & 39.1 \\
\hline
\end{tabular}

Table VI. Association between age and primary PCl outcome

\begin{tabular}{|c|c|c|c|c|}
\hline \multirow[b]{2}{*}{ Age (years)* } & \multicolumn{2}{|c|}{ Group } & \multirow{2}{*}{$\begin{array}{l}\text { Relative Risk } \\
\text { (95\% Cl of RR) }\end{array}$} & \multirow[b]{2}{*}{$p$-value } \\
\hline & $\begin{array}{c}\text { Unfavorable } \\
(\mathrm{n}=9)\end{array}$ & $\begin{array}{c}\text { Favorable } \\
(n=41)\end{array}$ & & \\
\hline$\geq 75$ & $6(66.7)$ & $7(17.1)$ & \multirow{2}{*}{$5.7(1.6-19.5)$} & \multirow{2}{*}{0.008} \\
\hline$<75$ & $3(33.3)$ & $34(82.9)$ & & \\
\hline
\end{tabular}

Figures in the parentheses indicate corresponding \%; *Chi-squared Test $\left(\chi^{2}\right)$ was done to analyze the data.

\section{DISCUSSION:}

The most appropriate reperfusion strategy for older patients is primary angioplasty that is performed within an acceptable time frame. ${ }^{14,7}$ However, the prognosis is still worse among elderly than among younger patients. ${ }^{15-20}$ In the present study, we used DES in $100 \%$ cases. Both DES and BMS were used for a single lesion in $8.0 \%$ cases where more than one stent was required. This was due to financial constraints, as 
patients could not afford a second DES. The 2017 ESC Guidelines for the management of STEMI, have stipulated implantation of DES over BMS with a Class I (level of evidence $A$ ) recommendation.

No access-site complications or haematomas were observed in the present study, because the radial access was the predominant (98\%) access-site used. This approach is well-supported by guideline recommendations. ${ }^{10}$ More than half cases was done through radial route in the study done by José et $a^{21}$ without experiencing much of the complication related to access site. Especially in case of PPCI, radial access is superior to femoral access, ${ }^{22-25}$ despite the fact that this approach could be more difficult in elderly patients, particularly in women due to subclavian tortuosity. The latter cases may necessitate cross-over to alternate access. These factors exert important potential impacts on clinical outcomes. ${ }^{26}$

Thrombus aspiration was done in 1 patient in our series, due to huge thrombus load as well as to facilitate distal perfusion. Thrombo-aspiration was done in more than half of the cases in José et al's study. ${ }^{21}$ It was not a predictor of adverse events in their study. Systematic application of this strategy failed to improve prognosis. ${ }^{27,28}$ However, its selective use might offer some advantages, particularly for the high-risk populations, such as elderly patients. An important determinant after PPCI is inadequate reperfusion which is associated with poor prognosis. ${ }^{29,30}$

Subgroup analysis of Primary Angioplasty in Myocardial Infarction-I (PAMI-I) revealed no increased risk of stroke and intracranial hemorrhage in the elderly patients, in their PCI group. ${ }^{31}$ This is also true for our population, where no such events were reported. In our 1 year follow up only $2(4.3 \%)$ patients developed ischaemic stroke, which is not related to the procedure.

In our study, approximately $30 \%$ of cases presented with a symptom onset of $>6$ hours. This feature was almost similar to that of
Hernández et al. ${ }^{21}$ In their study approximately $30 \%$ of the patients presented with chest pain of $>6$ hours duration. This finding was important because a delayed presentation of $>6$ hours was identified as a predictor of events in their study.

Eight percent $(8 \%)$ of our population had cardiogenic shock. The incidence of cardiogenic shock was $11.5 \%$ in the study of Hernández et al. ${ }^{21}$ Gharacholou and associates ${ }^{31}$ showed that older patients undergoing PPCI have lower rates of procedural success, and are more likely to suffer from post-procedural complications. They had $4.8 \%$ mortality in $65-74$ years and $13.1 \%$ mortality in the age group of $\geq 75$ years at 90 days follow up. According to the authors, age is the strongest predictor of mortality at 90 days. ${ }^{31}$ In our analysis advanced age (age $\geq 75$ years) was found as a predictor of in-hospital and one-year outcome with RR of developing unfavorable outcome was > 5-times (95\% CI: 1.6-19.5) higher in patients of advanced age than that in patients of age $<75$ years $(p=0.008)$. Our in-hospital mortality rate was $8 \%$. A subgroup analysis of PAMI-I trial also showed a fewer in-hospital deaths and a significant reduction in death or recurrent MI in patients aged $\geq 65$ years who underwent immediate PCI. ${ }^{31}$ Although our study did not include a comparison with fibrinolytic therapy, mortality following PPCI was very much consistent with that of PAMI-1.

The 1-month mortality seen in the registry done by Hernández et al. ${ }^{21}$ was $12.2 \%$. 2-year mortality rate of the registry done by Hernández et al. ${ }^{21}$ was $24.2 \%$, with a notable contribution of noncardiovascular mortality. This mortality rate was higher than that observed in the general population but is within the range published by other registries of this population. ${ }^{15,16,19,20,32-34}$ Mortality rate was increased by $6.67 \%$ in our population during the 1-year follow up period, all of which were due to non-cardiac causes. A review by Vimalraj et al reported non-cardiac causes as the predominant cause of death after all types of 
PCI in the very elderly population. ${ }^{35}$ The elderly may experience higher mortality from STEMI due to severe comorbidities, advanced coronary artery disease (CAD), as well as mechanical and electrical complications of acute myocardial infarction (AMI). ${ }^{32,33}$

The patients in our study were predominantly diabetic (78\%) and hypertensive (74\%) with 34\% developing ALVF, and $8.0 \%$ cardiogenic shock, which might have contributed to adverse outcomes. Rigorous selection criteria gave certain advantages to the acute phase elderly infarction survivors over the general population for adverse cardiac events. It was revealed in a large Swedish study in the follow up of subsequent year. ${ }^{15}$

The role of complete revascularization was important. In our study 34\% had DVD, 20\% had TVD. However, only $17.4 \%$ underwent further revascularization of non-culprit lesions either before discharge in the same admission or later with subsequent admission. Hernández ${ }^{21}$ showed that $55.4 \%$ of their patients had multivessel disease. In their study a sizable proportion of patients underwent revascularization of non-culprit lesions in the acute phase or as a subsequent procedure during admission. Over one-third (35.3\%) had significant residual disease at discharge. According to COMPLETE trial- complete revascularization (before or after the index hospitalization) after primary PCI for STEMI is beneficial and superior to culprit-only revascularization in reducing death or MI. ${ }^{30}$ There was no major bleeding during hospitalization or during 1 year follow up in our study. Hernández ${ }^{21}$ reported the incidence of major bleeding to be $0.5 \%$ at one month and $2.4 \%$ at 2 year follow up. ISR was observed in $2.2 \%$ cases during follow up, followed by target vessel revascularization (TVR). The incidence of repeat revascularization was low in Hernández's study, ${ }^{21}$ despite most of the patients receiving BMS. The incidence of stent thrombosis was $3.1 \%$. although we didn't have any incidence of stent thrombosis possibly due to deployment of DES in most cases.
The present study showed that the in-hospital survival rate of PPCI was $92 \%$. The overall mortality rate (in-hospital mortality plus 1-year mortality) in the present study was $14 \%$. Abdullah showed that their survival rate of PPCI patients was $86 \%$ at month 1 , followed by $83.9 \%$ at month 6 , and $81.2 \%$ at month $12 .{ }^{36}$ So from these evidences it could be postulated that patients treated with PPCI for STEMI have good prognosis if they survive the initial months. Before drawing conclusion, the following limitations deserve mention.

\section{Limitations:}

The sample size was too small to generalize the findings to reference population and the study was conducted a single center. Besides, we could not include the data of patients' adherence to drugs, as one year follow up was done over telephone.

\section{CONCLUSION:}

Primary PCI is a feasible treatment option for elderly Bangladeshi patients presenting with STEMI with fewer in-hospital and 1-year follow up deaths. Adverse cardiovascular events are even less. Advanced age is an important determinant of adverse cardiovascular events including mortality, probably because of more medical co-morbidities associated with advanced age.

\section{REFERENCES:}

1. Shanmugasundaram M. Percutaneous Coronary Intervention in Elderly Patients-Is It Beneficial? Tex Heart Inst J 2011;38(4):398-403.

2. Yancik R. Cancer burden in the aged: an epidemiologic \& demographic overview. Cancer 1997;80(7):1273-83.

3. Worldometer (www. Worldometers.info). Elaboration of data by United Nations, Department of Economic and Social Affairs, Population Division. World Population Prospects: The 2019 Revision. (Medium-fertility variant)

4. Gurwitz JH, Col NF, Avorn J. The exclusion of the elderly and women from clinical trials in acute myocardial infarction. JAMA 1992;268(11):1417-22.

5. Barikdar A, Ahmed T, Lasker SP. The Situation of the Elderly in Bangladesh. Bangladesh Journal of Bioethics 2016;7(1):27-36. 
6. Gupta TD. Fast growing old people bring new economic challenge. On the occasion of International Day of Older Persons, we take a look at the state of elderly people in Bangladesh. Last modified: 01 October, 2019, 03:22 pm. available at:https://tbsnews.net/feature/ wellbeing/aging-without-dignity-security

7. Brieger D, Eagle KA, Goodman SG, Steg PG, Budaj A, White K, Montalescot G. Acute coronary syndromes without chest pain, an underdiagnosed \& undertreated high risk group: insights from the Global Registry of Acute Coronary Events. Chest 2004;126(2):461-469.

8. Toleva O, Ibrahim Q, Brass N, Sookram S, Welsh R. Treatment choices in elderly patients with ST elevation myocardial infarction- insights from the Vital Heart Response registry. Open Heart 2015;2(1):e000235.

9. Malkin CJ, Prakash R, Chew DP. The impact of increased age on outcome from a strategy of early invasive management and revascularisation in patients with acute coronary syndromes: retrospective analysis study from the ACACIA registry. BMJ Open 2012;2 (1):e000540.

10. Ibanez B, James S, Agewall S, Antunes MJ, BucciarelliDucci C, Bueno H, Caforio ALP, Crea F, Goudevenos JA, Halvorsen S et al. 2017 ESC Guidelines for the management of acute myocardial infarction in patients presenting with ST-segment elevation : The Task Force for the management of acute myocardial infarction in patients presenting with ST-segment elevation of the European Society of Cardiology (ESC). European Heart Journal 2018;39(2):119-177.

11. Bueno H, Betriu A, Heras M, Alonso JJ, Cequier A, Garcia EJ, Lopez-Sendon JL, Macaya C, Hernandez-Antolin R, TRIANA Investigators. Primary angioplasty vs. fibrinolysis in very old patients with acute myocardial infarction: TRIANA (TRatamiento del Infarto Agudo de miocardio eN Ancianos) randomized trial and pooled analysis with previous studies. Eur Heart J 2011;32 (1):51-60.

12. Kinsella K. Urban and rural dimensions of global population aging: an overview. J Rural Health 2001;17(4):314-22.

13. Lee KL, Woodlief LH, Topol EJ, Weaver WD, Betriu A, Col $\mathrm{J}$, et al. Predictors of 30-day mortality in the era of reperfusion for acute myocardial infarction. Results from an international trial of 41,021 patients. GUSTO-I Investigators. Circulation 1995;91(6):1659-68.

14. O'Gara PT, Kushner FG, Ascheim DD, Casey DE, Chung MK, de Lemos JA et al. 2013 ACCF/AHA Guideline for the Management of ST-Elevation Myocardial Infarction: a Report of the American College of Cardiology Foundation/American Heart Association Task Force on Practice Guidelines. J Am Coll Cardiol 2013;61: e78-e140.

15. Velders MA, James SK, Libungan B, Sarno G, Fröbert O, Carlsson $\mathrm{J}$ et al. Prognosis of elderly patients with ST elevation myocardial infarction treated with primary percutaneous coronary intervention in 2001-2011: a report from the Swedish Coronary Angiography and Angioplasty Registry (SCAAR) registry. Am Heart J 2014; 167:666-673.

16. Kvakkestad KM, Abdelnoor M, Claussen PA, Eritsland J, Fossum E, Halvorsen $S$. Long-term survival in octogenarians and older patients with ST-elevation myocardial infarction in the era ofprimary angioplasty: a prospective cohort study. Eur Heart J Acute Cardiovasc Care 2016;5:243-252.

17. Dziewierz Z, Siudak T, Rakowski JS, Dubiel D. Dudek. Age-related differences in treatment strategies and clinical outcomes in unselected cohort of patients with ST-segment elevation myocardial infarction transferred for primary angioplasty. J Thromb Thrombolysis 2012;34:214-221.

18. De Geare VS, Stone GW, Grines L, Brodie R, Cox DA, Garcia E et al. Angiographic and clinical characteristics associated with increased in-hospital mortality in elderly patients with acute myocardial infarction undergoing percutaneous intervention (a pooled analysis of the primary angioplasty in myocardial infarction trials). Am J Cardiol 2000;86:30-34.

19. Forman DE, Chen AY, Wiviott SD, Wang TY, Magid DJ, Alexander KP. Comparison of outcomes in patients aged $<75,75$ to 84 , and $\geq 85$ years with ST-elevation myocardial infarction (from the ACTION Registry-GWTG). Am J Cardiol 2010;106:1382-1388.

20. Claessen BE, Kikkert WJ, Engstrom AE, Hoebers LPC, Damman $\mathrm{P}$, Vis $\mathrm{MM}$ et al. Primary percutaneous coronary intervention for ST elevation myocardial infarction in octogenarians: trends and outcomes. Heart 2010;96:843-847.

21. Hernández JMT, Brugaletta S, Joan A. Gómez Hospital, José A. Baz, Armando Pérez de Prado, Ramón López Palop et al. Primary Angioplasty in Patients Older Than 75 Years. Profile of Patients and Procedures, Outcomes, and Predictors of Prognosis in the ESTROFA IM +75 Registry. Rev Esp Cardiol 2017;70(2):81-87.

22. Karrowni W, Vyas A, Giacomino B, Schweizer M, Blevins A, Girotra $S$ et al. Radial versus femoral access for primary percutaneous interventions in ST-segment elevation myocardial infarction patients: a metaanalysis of randomized controlled trials. JACC Cardiovasc Interv 2013;6:814-23.

23. Bernat I, Horak D, Stasek J, Mates M, Pesek J, Ostadal $P$ et al. ST-segment elevation myocardial infarction 
treated by radial or femoral approach in a multicenter randomized clinical trial: the STEMI-RADIAL trial. J Am Coll Cardiol 2014;63:964-72.

24. Valgimigli M, Gagnor A, Calabró P, Frigoli E, Leonardi S, Zaro $T$ et al, Radial versus femoral access in patients with acute coronary syndromes undergoing invasive management: a randomised multicentre trial. Lancet 2015;385:2465-76

25. Marti V, Brugaletta S, García-Picart J, et al, en representación de los investigadores del estudio Examination. Acceso radial frente a femoral en angioplastia por infarto agudo de miocardio con elevación del segmento ST con stent farmacoactivo de segunda generación. Rev Esp Cardiol 2015;68:47-53.

26. Hermandez-Pérez FJ, Blasco-Lobo A, Goicolea L, et al. El uso del acceso radial en la angioplastia primaria: resultados en 1.029 pacientes consecutivos y análisis en subgrupos desfavorables. Rev Esp Cardiol 2014;67 :45-51.

27. Lagerqvist B, Fröbert O, Olivecrona GK, et al. Outcomes 1 year after thrombus aspiration for myocardial infarction. N Engl J Med 2014;371:1111-20.

28. Jolly SS, Cairns JA, Yusuf $S$, et al, for the TOTAL Investigators. Randomized trial of primary PCI with or without routine manual thrombectomy. N Engl J Med 2015;372:1389-98.

29. De Luca G, Van't Hof AW, Ottervanger JP, et al. Ageing, impaired myocardial perfusion, and mortality in patients with ST-segment elevation myocardial infarction treated by primary angioplasty. Eur Heart J $2005 ; 26: 662-6$.

30. Anthony A, Kim B, Eagle A. Complete Versus Culprit-Only Revascularization Strategies to Treat Multivessel Disease After Early PCI for STEMICOMPLETE. American College of Cardiology. 2019.
31. Stone GW, Grines CL, Browne KF, Marco J, Rothbaum D, O'Keefe J, et al. Predictors of in-hospital and 6-month outcome after acute myocardial infarction in the reperfusion era: the Primary Angioplasty in Myocardial Infarction (PAMI) trial. J Am Coll Cardiol 1995;25(2): $370-7$.

32. Alexander KP, Newby LK, Armstrong PW, Cannon CP Gibler WB, Rich MW. Acute coronary care in the elderly, part II: ST-segment-elevation myocardial infarction: a scientific statement for healthcare professionals from the American Heart Association Council on Clinical Cardiology: in collaboration with the Society of Geriatric Cardiology. Circulation 2007;115(19):2570-2589.

33. Bauer $T$, Möllmann $H$, Weidinger $F$, Zeymer $U$, SeabraGomes R, Eberli F. Predictors of hospital mortality in the elderly undergoing percutaneous coronary intervention for acute coronary syndromes and stable angina. Int J Cardiol 2011;151(2):164-169.

34. Dangas GD, Singh HS. Primary percutaneous coronary intervention in octogenarians: navigate with caution. Heart 2010;96:813-814.

35. Vimalraj BS, Richard H, Ian M, Yuvaraj M, Peter JP. An overview of PCI in the very elderly. J Geriatr Cardiol 2015;12(2):174-184

36. Abdullah K, Sanjay M, Andrew S, Robert IC. Prognosis of primary percutaneous coronary intervention in elderly patients with ST-elevation myocardial infarction. J Saudi Heart Assoc 2015;27(2): 85-90. 